\title{
Reflexiones en torno a la autenticidad de las tradiciones. Títulos Primordiales y kastom polinesia
}

\author{
Paula López Caballero \\ Escuela de Altos Estudios en Ciencias Sociales, París \\ paula.lopez-caballero@ehess.fr
}

\begin{abstract}
Resumen
En este artículo proponemos revisar la noción de tradición a partir de la comparación de dos conjuntos de textos aparentemente distintos: 1) un problema antropológico: la aparición de las tradiciones llamadas "inventadas" en las islas del Pacífico sur (kastom); y 2) los discursos de los Títulos Primordiales escritos por los nahuas de México en los siglos XVII y XVIII. El punto en común entre estas realidades tan diferentes es la sospecha que pesa sobre ambos discursos nativos: ¿pueden considerarse auténticos a pesar de que están vinculados a procesos políticos? La tesis que se busca demostrar aquí es que separar autenticidad y compromisos políticos responde más a una perspectiva de los especialistas de cada región que a hechos percibidos en el trabajo de campo o en el de archivo. Este texto insiste también en la importancia de ofrecer análisis interdisciplinarios -antropología e historia, en este caso-, así como interregionales -México y las islas de Oceanía.

Palabras clave: TÍTULOS PRIMORDIALES, KASTOM, MÉXICO, POLINESIA, SIGLO XVII, SIGLO XVIII.
\end{abstract}

\begin{abstract}
Here we intend to examine the concept of tradition taking as a starting point the comparison between two groups of seemingly different texts: 1) the anthropological problem: the appearance of the traditions called "invented" in the islands of the south Pacific (kastom); and 2) the discourse of the Primordial Titles written by the Nahuas of Mexico in the XVII and XVIII centuries. The common point between these realities is the suspicion that exists over both native discourses: Can they be considered authentic although they are linked to political processes? The thesis to demonstrate here is that separate authenticity and political commitments responds more to a perspective of each region's specialists than to facts perceived in the field work or in the files search. This text also insists in the importance of multidisciplinary analysis -in this case between anthropology and history- and multiregional examples -in this paper Mexico and Oceania.

Key words: PRIMORDIAL TITLES, KASTOM, MEXICO, POLYNESIA, $17^{\mathrm{TH}}$ CENTURY, $18^{\mathrm{TH}}$ CENTURY.
\end{abstract}


Los académicos occidentales han hecho de Hawai un folclore, proyecto que, en el siglo pasado, incluyó a muchos intelectuales nativos. Pero ese es el pasado definido y controlado por Occidente, el pasado objetivo. Por eso, para el experto, el Hawai moderno así como los simulacros para turistas carecen igualmente de autenticidad. (...) Desde este punto de vista, la cultura hawaiana, auténtica, dejó de existir al iniciar el siglo XX.

Jonathan Friedman, "The past into the present..."

\section{Introducción}

Desde hace por lo menos treinta años, en diversos lugares del mundo, han sido múltiples las manifestaciones de los grupos étnicos que basan sus demandas y su participación políticas en las especificidades culturales que los identifican. Constantemente, estas luchas se organizan en torno a la afirmación y defensa de una cultura tradicional, de origen inmemorial que se materializa en cierto número de prácticas, como un tipo particular de agricultura, mitos, rituales, pero, sobre todo, una historia común ${ }^{1}$.

\footnotetext{
${ }^{1}$ Para Oceanía, véase Alain Babadzan, "Kastom and Nation Building in the South Pacific", en Processes of Interthnic Relations in Latin America, Southeast Asia and the Pacific. F. P. y S. T., ed. Remo Guidieri (Houston: Rothko Chapel y University of Texas Press, 1988), 199-228; Jonathan Friedman, "The Past in the Future: History and Politics of Identity", American Anthropologist (Catalunya), 94, núm. 4 (1992): 837-859; "Will the Real Hawaiian Please Stand: Anthropologists and Natives in the Global Struggle for Identity", Bijdragen Tot de Taal-Land, en Volkenkunde. Núm. especial: Politics, Traditions and Change in the Pacific (Leiden), 149 (1993): 737-767; Cultural Identity and Global Processes (London: Sage Publications, 1994); "From roots to routes. Tropes for trippers", Anthropological Theory (Londres), 2, núm. 1 (2002): 21-36; "Modernity and Other Traditions", en Critically Modern. Alternatives, Alterities, Anthropologies, ed. B. M. Knauft (Bloomington, Indianapolis: Indiana University Press, 2002); Alan Hanson, "The Making of the Maori: Cultural Invention and its Logic", American Anthropologist (Washington D. C.), 91, núm. 4 (1989): 890-902; Margaret Jolly, "Specters of Inauthenticity", The Contemporary Pacific (Honolulu), 4, núm. 1(1992): 42-72; Jonathan Kamakawiwo'ole Osorio, ""What Kine Hawaiian Are You?" A Mo'oleo about Nationhood, Race, History, and the Contemporary Sovereignty Movement in Hawai'i", The Contemporary Pacific (Honolulu), 13, núm. 2 (2001): 359-379; Roger Keesing, "Kastom in Melanesia: An Overview", Mankind. Núm. especial. Reinventing Traditional Culture: The Politics of Kastom in Island Melanesia, eds. Roger Keesing y Robert Tonkinson (1982), 13: 1-5; "Creating the Past: Custom and Identity in the Contemporary Pacific", The Contemporary Pacific (Honolulu), núm. 1 (1989): 19-42; Stephanie Lawson, "The Tyranny of Tradition: Critical Reflections on Nationalist Narratives in the South Pacific", en Narratives of Nation in the South Pacific, eds. T. Otto y N. Thomas (Amsterdam: Harwood
} 
En este artículo nos interesa exponer algunos problemas que se desprenden de estos movimientos de reidentificación étnica para las ciencias sociales. Las líneas que guiarán este análisis tratarán sobre la utilización política de las tradiciones (y, por tanto, de la cultura) en contextos de autodefinición de los grupos étnicos. ¿Qué sucede cuando un grupo indígena toma la palabra para dibujar y definir su identidad y crea una imagen contradictoria con aquello que los especialistas de la región dicen de esos mismos grupos?, ¿es posible que un grupo social redefina sus propias tradiciones frente a un conflicto político específico? Y de ser así, ¿siguen siendo auténticas esas tradiciones? En suma, nos interesa analizar los problemas que se presentan cuando un grupo social (particularmente, étnico) se observa y proyecta esa mirada al exterior del grupo con la intención de definirse y ocupar un lugar dentro de contextos políticos más amplios.

Academic Publishers, 1997), vol. 19: 15-31; Jocelyn Linnekin, "Defining Tradition: Variations on the Hawaiian Identity", American Ethnologist (Arlington, Estados Unidos), 10 (1983): 241-252; "Cultural Invention and the Dilemma of Authenticity", American Anthropologist (Washington D. C.), 93 (1991):446-448; "On the Theory and Politics of Cultural Construction in the Pacific", Oceania. Special Issue: The Politics of Tradition in the Pacific (Sidney, Australia), 62, núm. 4 (1992): 249-263; Jocelyn Linnekin y Lin Poyer, eds., Cultural Identity and Ehtnicity in the Pacific (Honolulu: University of Hawai'i Press, 1990); Nicholas Thomas, "The inversion of tradition", American Ethnologist (Arlington, Estados Unidos), 19, núm. 2 (1992): 213-232; James West Turner, "Continuity and Constraint: Reconstructing the Concept of Tradition from a Pacific Perspective", The Contemporary Pacific (Honolulu), 9, núm. 2 (1997): 345-381; S. Webster, "Postmodernist Theory and the Sublimation of Maori Culture", Oceania (Sidney, Australia), 63 (1993): 222-239; David Welchman Gegeo, "Cultural Rupture and Indigeneity: The Challenge of (Re)visioning "Place" in the Pacific", The Contemporary Pacific (Honolulu), 13, núm. 2 (2001): 491-507; Éric Wittersheim, "Les chemins de l'authenticité. Les anthropologues et la Renaissance mélanésienne", L'Homme (París), 151(1999): 181-206. Para Latinoamérica, véanse, entre otros, Edward F. Fischer y R. Mckeena Brown, eds., Mayan Cultural Activism in Guatemala (Austin, Texas: Austin University Press, 1996); Joe Foweraker y Ann Craig, eds., Popular Movements and Political Change in Mexico (Boulder: Rienner, 1990); Jonathan Fox, ed., The Challenge of Rural Democratisation: Perspectives from Latin America and the Philippines (Londres: Cass, 1990); Daniel Levine, ed., Constructing culture and Power in Latin America (Michigan: Michigan University Press, 1993); Maybury-Lewis, David. Indigenous Peoples, Ethnic Groupes and the State (Boston: Allyn and Bacon, 1997); Greg Urban y Joel Sherzer, eds., Nation States and Indians in Latin America (Austin, Texas: Austin University Press, 1991); Donna Lee Van Cott, ed., Indigenous Peoples and Democracy in Latin America (Nueva York: St. Martin's Press, Inter-American Dialogue, 1994); Kay Warren, The Simbolism of Subordination: Indian Identity in a Guatemala Town (Austin, Texas: University of Texas Press, 1989); Indigenous Movements and their Critics: Pan-Mayan activism in Guatemala (Princeton, N J: Princeton University Presspp, 1998). 
Para ello presentaremos dos debates académicos muy distintos a través de los cuales veremos, de manera particularmente clara, las interrogantes que nos interesan. Por un lado, la discusión sobre las "tradiciones inventadas" en Oceanía (Hawai, Fiji, Melanesia y Polinesia) desplegadas por los grupos étnicos a lo largo de las tres últimas décadas. Frente al auge de estas nuevas tradiciones (kastom) que los grupos étnicos generaron con el fin de adquirir mayores derechos políticos, los antropólogos trataron de entender esos nuevos discursos políticos articulados en torno a la cultura tradicional. Sin embargo, para la mayoría de los especialistas, el análisis de dichas expresiones políticas se redujo a una competencia de conocimiento entre los especialistas de cada región -que no veían en estos discursos más que una invención o una reificación de la cultura propia- y los portavoces indígenas que afirmaban su derecho a autodefinirse.

Por otro lado, presentaremos la discusión sobre los Títulos Primordiales del centro de México, un corpus de documentos indígenas coloniales de los siglos XVII y XVIII. En estos textos, los grupos nahuas de dicha región reinterpretan y utilizan su historia para exigir derechos relativos a la propiedad de la tierra que pertenecía a los diferentes pueblos. En este sentido, es posible hablar de los títulos como una expresión de la manera en que estos indígenas percibían su historia y su presente, redactados con fines políticos. Curiosamente, en este segundo caso la versión nativa también es confrontada con la que los especialistas conocen; la autenticidad de las narraciones contenidas en estos documentos también ha sido debatida por distintos historiadores.

En ambos corpus, a pesar de la distancia geográfica y temporal que los separa, el común denominador es la sospecha que pesa sobre ellos en el análisis de los investigadores: ¿pueden estas tradiciones "inventadas" considerarse auténticas a pesar de estar vinculadas a procesos políticos y de ser tan diferentes de las versiones científicas? Esta polémica, dentro del medio académico, fue particularmente fructuosa en el debate de Oceanía y dio origen a una serie de propuestas y perspectivas novedosas sobre la cuestión. Por ello, el ejercicio que proponemos será retomar la discusión sobre la autenticidad de las tradiciones en el Pacífico sur y utilizarla para entender mejor los contenidos de los Títulos Primordiales. Dos ejes guiarán, entonces, el presente análisis: en primer lugar, trataremos de entender por qué los estudiosos de ambos contextos -la Oceanía contemporánea y el México colonial- consideran falsos los discursos identitarios expresados por estos grupos étnicos. En un segundo momento, el objetivo de este trabajo será destacar la dimensión política de las tradiciones, lo cual nos permitirá definirlas como revisiones del pasado, siempre vinculadas a una reconstrucción de la identidad y que funcionan, necesariamente, como un proyecto político y social para el futuro. 
Para ello, expondremos las características de ambos procesos histórico-sociales, la kastom y los Títulos Primordiales. La discusión principal que articula ambos corpus girará, entonces, alrededor de la utilización política de la cultura, de las tradiciones e historias locales expresadas con fines concretos y políticos y de las dudas que ello suscitó (y suscita) en el medio académico, es decir, la percepción y análisis que de ellos han hecho los especialistas.

Contrariamente a la opinión de la mayoría de los autores que han trabajado con los títulos o con las tradiciones "inventadas" de Oceanía, nuestra hipótesis sostiene que el aspecto pragmático de estas tradiciones y su autenticidad no son cualidades excluyentes. Es decir, trataremos de mostrar que ambas manifestaciones nativas son al mismo tiempo una estrategia política y una narración valiosa y genuina para los grupos que las sostuvieron. Uno de los fundamentos de este argumento está vinculado a una noción particular de cambio cultural que entiende las novedades y préstamos culturales como resultado de las transformaciones sociales y no como manipulaciones calculadas para alcanzar las metas deseadas.

Procederemos, entonces, a una síntesis del origen de los títulos y una breve descripción de los mismos para así poder mostrar cuáles han sido las posturas de aquellos investigadores que se han acercado a este corpus documental. En un segundo momento, se discutirá la controversia suscitada en la región de Oceanía con respecto a las tradiciones inventadas $\mathrm{y}$, por último, en la conclusión retomaremos las propuestas surgidas de este debate y que pueden contribuir tanto a la discusión sobre los títulos como a un nuevo planteamiento del problema más amplio de la utilización política de la cultura² ${ }^{2}$.

\section{Los Títulos Primordiales del centro de México, ¿narraciones auténticas?}

A partir de la segunda mitad del siglo XVII, casi un siglo y medio después de la conquista, las comunidades indígenas de los valles centrales de la Nueva España (nahuas, en su mayoría) veían amenazada su posibilidad de acceso a la tierra. Muchos son los factores que intervienen en este proceso; sin embargo, resultan fundamentales la expansión de las haciendas españolas y la recuperación demográfica de la población nativa tras la crisis que sufrió debido a las epidemias de los siglos XVI y XVII.

\footnotetext{
${ }^{2}$ Cabe aclarar de antemano que, si bien es deseable el estudio puntual de cada Título Primordial, el examen que aquí se realiza tanto de los títulos como de la kastom no pretende incluir una revisión exhaustiva de cada caso particular, sino de conjuntos discursivos que nos permitan abstraer algunas conclusiones teóricas.
} 
Frente a esta coyuntura (y contrariamente a las ideas de pasividad y depresión que muchas veces se asocian a los grupos indígenas durante el período colonial), las comunidades de esta región llevaron a cabo gran cantidad de procesos legales para proteger aquello que, a sus ojos, garantizaba su continuidad: la tierra. Una parte fundamental de estos procesos era la exhibición de documentos que probaran los linderos de las tierras correspondientes a cada comunidad. En principio, estos documentos deberían ser los otorgados por los primeros virreyes españoles en el siglo XVI, cuando se fundaron, ratificaron o congregaron la mayoría de estos pueblos. De hecho, en general, los títulos de un pueblo son exactamente eso: las mercedes, vistas de ojo y demás documentación oficial expedida por las autoridades coloniales que reconocen las tierras de cada pueblo.

Sin embargo, los Títulos Primordiales del centro de México, aunque guardan semejanza con este tipo de documentos, son diferentes al corpus que acabamos de describir. Estos títulos pertenecen a varios pueblos ubicados dentro una extensa área que corre desde el valle de Toluca hasta Chalco, pasando por Tlalpan, Xochimilco, Milpa alta y Cuernavaca. Aparentemente, estos manuscritos tuvieron la función de subsanar el vacío dejado por la pérdida o ausencia de los documentos originales del siglo XVI, necesarios para cualquier procedimiento administrativo o judicial relativo a la tenencia de la tierra. La mayoría de ellos se encuentran en el Archivo General de la Nación (AGN) dentro de litigios por problemas de límites territoriales entre haciendas y pueblos, entre cabeceras y sujetos o entre pueblos vecinos $^{3}$.

Pero, sin duda, la característica más singular de estos documentos es que incluyen información que no puede encontrarse en ninguno de los ya mencionados: una historia del pueblo a partir de la conquista y una cosmovisión propia. Además, la mayoría de ellos fueron redactados en náhuatl por miembros de los mismos pueblos indios ${ }^{4}$. El hilo conductor de los relatos es la descripción y defensa de los límites territoriales de cada pueblo. Además, hay una narración de los hechos

\footnotetext{
${ }^{3}$ En la mayoría de los casos no se conoce información documental sobre los autores, las fechas o los motivos de su factura, lo único que consta es su presencia en los pleitos agrarios. De ahí las especulaciones sobre su autenticidad.

${ }^{4}$ Esta cuestión forma parte de la polémica que expondremos más adelante. Para algunos historiadores, los títulos fueron elaborados en talleres por profesionales que los vendían a los pueblos. Stephanie Wood, "Don Diego García Mendoza: A Techialoyan Mastermind?", Estudios de Cultura Náhuatl (México), 19 (1989): 245-268; "El problema de la historicidad de los títulos y los códices Techialoyan", en De Tlacuilos y escribanos. Estudios sobre documentos indígenas coloniales del centro de México, Colección Memorias. Zamora, eds. X. Noguez y S. Wood (Michoacán Zinacantepec, Estado de México: El Colegio de Michoacán; El Colegio Mexiquense, 1998), 1-221; "The Social against the Legal Context of Nahuatl títulos", en Native Traditions in the Postconquest World. T.C., ed., Elizabeth Hill Boone (Washington D. C.: Dumbarton Oaks, 1998), 201-231.
} 
principales de la historia local: la fundación del pueblo, el bautizo, la congregación, $\mathrm{y}$ otras transformaciones importantes para el pueblo, hasta convertirse en lo que es al momento de presentar sus títulos.

Entonces, además de ser un ejemplo de la participación política y jurídica de dichos grupos en el contexto colonial, el enorme valor de este corpus reside, principalmente, en que albergan una interpretación indígena de la historia y del mundo colonial en su período tardío (fines del siglo XVII-XVIII) ${ }^{5}$.

En este trabajo, entonces, el énfasis se pondrá en la manera en que los pueblos nahuas del centro de México apelaron a su historia, a su pasado, para argumentar y luchar por la posesión de la tierra. En este sentido, sostendremos que en los títulos, las tradiciones locales fueron utilizadas con un fin preciso: la defensa de la tierra.

En cuanto a los contenidos de estos manuscritos, una primera lectura puede resultar desconcertante debido a la aparente ambigüedad de la información disponible (de hecho, esta es una de las razones que motivaron la polémica sobre su falsedad). De manera muy sucinta, esta heterodoxia puede resumirse en tres aspectos principales: 1) todos los títulos dicen tener una antigüedad difícilmente comprobable e incluyen gran cantidad de fechas de fundación, ratificación, congregación, que no pueden demostrarse; 2) los autores anónimos de estos documentos muestran una visión muy positiva de la conquista y del proceso de colonización que le siguió (en su aspecto tanto civil como religioso) así como de sus actores principales: Cortés, los primeros virreyes, los primeros frailes; 3 ) en los títulos hay una mezcla de hechos "históricos" y sucesos "sobrenaturales" - la aparición de santos, mensajes divinos, sueños- incorporados al mismo nivel de la narración ${ }^{6}$.

En lo que respecta al carácter formal de estos documentos, diremos únicamente que las narraciones de los títulos se articulan con un discurso oral ${ }^{7}$. Aunque es muy

\footnotetext{
${ }^{5}$ Ciertamente, existe un buen número de textos producidos por indígenas que narran la historia indígena y colonial; sin embargo, la gran mayoría de ellos pertenecen al siglo XVI, a los primeros tiempos de la evangelización y colonización. De ahí la originalidad de los títulos. A partir del siglo XVII, además de los Títulos Primordiales, cabe mencionar los códices Techialoyan, si bien la problemática que los rodea y los contextos en que fueron realizados difieren de aquellos, pues hay una evidente intención en estos: los trazos de los dibujos fingen ser antiguos y el papel está ennegrecido. No es el caso de los títulos.

${ }^{6}$ A pesar de que estas características las comparten la mayoría de los documentos, existen excepciones, como el Título Primordial de Santo Tomás Ajusco. Paula López, Los Títulos Primordiales del centro de México. Introducción y catálogo (México: Dirección General de Publicaciones; Conaculta, 2003), 192.

7 No hay lugar en este artículo para demostrar con detalle los elementos de oralidad encontrados en los títulos; sin embargo, sostenemos que están conformados por narraciones orales puestas por escrito con el fin de satisfacer necesidades concretas. Para un desarrollo
} 
posible que se utilizaran otros documentos para su redacción, varios indicios nos hablan de la fuerte raíz oral de los relatos contenidos en los títulos. Las fórmulas de enunciación que utilizan, así como las estructuras narrativas que organizan la narración, remiten a textos orales ${ }^{8}$. En nuestro análisis, resulta fundamental señalar las estructuras orales de narración de los títulos. Si aceptamos que el sistema privilegiado para guardar y transmitir la información de estos grupos fue el oral, podemos suponer, igualmente, que los textos escritos que conocemos fueron hechos para ser presentados ante las cortes judiciales.

Veremos ahora de qué hablan los Títulos Primordiales, sin olvidar que el sentido primero de estas narraciones es la posesión y protección de las tierras del pueblo, del tal suerte que todos los eventos se articulan alrededor de la dotación de la tierra y de las distintas etapas por las que el pueblo pasó desde la conquista hasta su presente.

El primer ejemplo es la llegada de los españoles, la conquista de México y la instauración de un nuevo orden. Para la mayoría de los pueblos, este episodio se concibe como el momento fundador, el momento de la demarcación de los linderos y de la concesión de mercedes. En los pasajes relativos a este evento, la Conquista se representa como un incidente, si no benéfico, por lo menos útil: la tierra de cada pueblo ha sido delimitada y distribuida.

Y ahora sabed, amados hijos míos, que cuando la cristiandad llegó a México fueron escogidos los que habían de gobernar cuando en México en Santiago Tlatelolco [sitio o lugar de promontorios de tierra] se hizo la guerra se decidieron ochenta días y doce días se respiro valor tomando en la mano armas de palos imponentes. En cinco de agosto de 1521 años así también aquí se hizo la guerra se formaron armas de palos amenazantes con los cuales se reconocieron las tierras en el rededor de los cerros, los montes donde acaban las lomas todas de Atlauhtla traspasando el camino?.

de los orígenes orales de los mismos, véanse Serge Gruzinski, La colonización de lo imaginario. Sociedades indígenas y occidentalización en el México español. Siglos XVI, XVIII (México: Fondo de Cultura Económica, 1993); James Lockhart, The Nahuas after the Conquest. A Social and Cultural History of Indians of Central Mexico 16th through 18th Centuries (Standford, California: Standford University Press, 1992); López, Los Títulos Primordiales.

${ }^{8}$ Casi sobra aclarar que, cuando hablamos de oralidad, en ningún momento se excluye la intervención de otros sistemas de transmisión, como la escritura y la imagen. Así, una hipótesis posible es que las narraciones de los títulos fueron los discursos que se hacían delante de las llamadas "pinturas" de los indios, en una interacción de los dos sistemas de transmisión. A este respecto, véase Federico Navarrete, "Mito, historia y legitimidad política: las migraciones de los pueblos del valle de México" (Tesis doctoral, UNAM, México, 2001).

${ }^{9}$ Título Primordial de San Miguel Atlauhtla. López, Los Títulos Primordiales, 346. 
Otro momento importante en los títulos es la congregación. Esta es evocada como una nueva fundación del pueblo, validada por las nuevas autoridades españolas. Este suceso legitima la constitución del pueblo frente a sus habitantes y, lejos de parecerles una amenaza, es percibido como un arma más para proteger el territorio que poseen.

La llamada conquista espiritual también juega un papel importante dentro de la argumentación de los autores de los títulos. Los hechos narrados a este respecto abordan dos temas principales: la construcción de la iglesia y la elección del santo patrono del pueblo, siempre vinculados a la obtención y posesión de la tierra. El santo siempre se percibe como un padre protector del pueblo, como su personificación misma: es el representante de la religión en el pueblo y también frente a los pueblos vecinos. Pero tal vez lo más notorio es que todos los hechos relacionados con la Iglesia cristiana y con la religión se presentan en los títulos como un asunto interno y autónomo del pueblo. La elección del santo así como la erección de iglesias y capillas la realizan los indios mismos. En la mayoría de los documentos, incluso, el santo decide hablar directamente con los ancianos de cada pueblo para informarles que él los ha elegido como feligreses. Envía señales y, en algunos casos, les ofrece la tierra tan añorada. Pero, al lado de esta cercanía con los santos y la religión católica, ni los españoles ni en particular los frailes aparecen en escena. Por lo demás, ese momento es, obviamente, una ratificación de las propiedades del pueblo. En el siguiente ejemplo se ve la manera en que el santo personifica al pueblo: "Aquí se pone la memoria de la voluntad de nuestro querido padre santo San Pablo y las tierras que hay en Ocotepeque son del santo San Pablo para sí y no en algún tiempo haya quien diga que son suyas" $"$.

Otro episodio recurrente y de gran importancia en los títulos es la enfermedad, la epidemia. En algunos casos, se la representa como un castigo divino, pero en la mayoría es uno más de los eslabones que constituyen la cadena de argumentos a favor de la posesión de la tierra. Así pues, la epidemia aparece en casi todos los títulos para justificar una nueva congregación y, por lo tanto, una nueva repartición de la tierra.

Y ahora sepan todos cuando la grande enfermedad que vino y murieron todos los del pueblo que fue cuando vino don Antonio de Mendoza virrey, que fue cuando fueron a México todos los viejos fue cuando murieron muchos. Y se les dio y perdonó por el Rey de no pagar los reales tributos y así mismo mandó que ninguno cogiera tierras que antes tenían los viejos ni se apropiaran de ella ninguno de los naturales ni español hasta que fueran criándose los naturales ${ }^{11}$.

${ }^{10}$ Título Primordial de San Pablo Chapultepec, en ibídem, 153.

${ }^{11}$ Título Primordial de San Juan Tenango Tepopula, en ibídem, 328. 
Es importante hacer referencia a los elementos olvidados, aquellos que los autores de los títulos omitieron, también elementos constitutivos del recuerdo y de la historia. Un ejemplo es que, prácticamente, no hay escenas en estos manuscritos en la que indios y españoles interactúen directamente después de la conquista o la congregación. Aun si el consejo de los ancianos siempre insiste en desconfiar de los hacendados europeos, estos no tienen una dimensión histórica en el relato: siempre aparecen como personajes lejanos, sin nombre, sin hechos concretos. Frente a estas entidades abstractas, la presencia española se conceptualiza como un conjunto de personajes importantes, que el tiempo y las transformaciones de los grupos indígenas no han eliminado de la memoria. Así, los nombres de Hernán Cortés, Luis de Velasco, Antonio de Mendoza o Juan de Zumárraga, entre otros, inundan el discurso de los títulos.

Otro aspecto que los autores de los títulos ignoran casi por completo es la historia del imperio mexicano y su caída, así como los subsecuentes gobiernos españoles, a menos que ello incida directamente en la formación del pueblo, en la ratificación de sus tierras o en la argumentación general que presentan. Por último, hay un vacío general en lo que respecta al lugar común de la historiografía sobre los indios coloniales: la supuesta desgracia que implicó la conquista primero y luego el orden colonial para los grupos indígenas de la región central de México. En todos los títulos, excepto en uno, la presencia de los españoles se articula al discurso para fortalecer las demandas del pueblo o como una amenaza lejana. Pero ni la conquista ni la evangelización ni el gobierno español son vistos como algo lamentable. Incluso, en algunos títulos se habla del pasado prehispánico y, en esos casos, no hay ninguna nostalgia, ningún sentimiento de pérdida.

La evidente subjetividad de las narraciones, así como los usos que las comunidades indígenas dieron a estos documentos han dado pie a que los historiadores que se han acercado a estos documentos se pregunten qué funciones tuvieron y cuál pudo ser la intención de los autores ${ }^{12}$. Efectivamente, desde una perspectiva histórica

\footnotetext{
12 En este trabajo nos limitamos a presentar las interpretaciones dominantes que se han hecho de los títulos, aunque vale la pena mencionar otros historiadores que se adscriben a alguna de ellas y que no serán analizados aquí. Entre otros, Enrique Florescano, "El canon memorioso forjado por los títulos primordiales", Colonial Latin American Historical Review (Hamilton, Estados Unidos), 11, núm. 2 (2002): 183-230; Robert Haskett, "Indian Town Government in Colonial Cuernavaca", The Hispanic American Historical Review (Durham: Estados Unidos), 67(1987): 203-231; "Visions of Municipal Glory Undimmed: The Nahuatl Town Histories of Colonial Cuernavaca", Colonial Latin American Historical Review (Albuquerque, Estados Unidos), 1, núm. 1 (1992): 1-35; Michel R. Oudijk y M. Romero Frizzi, "Los títulos primordiales: un género de tradición mesoamericana", Relaciones (Zamora, México), 24, núm. 95 (2003): 17-43; Hans Roskamp, "Los 'títulos primordiales' y la fundación prehispánica de los pueblos michoacanos: algunas reflexiones", Boletín del Archivo General Agrario (México), 15 (2001): 5-21.
} 
estricta, este corpus implica retos mayores que las fuentes primarias convencionales puesto que no tienen autor explícito ni fechas comprobables de la elaboración o de los sucesos narrados. Así, autores como Charles Gibson -el primero en mencionarlos como fuentes documentales- consideraron que si bien podrían tratarse de "memorias individuales o colectivas de la posesión de la tierra o de aquellas poseídas y luego perdidas", esta memoria "pudo ser errónea o transformada deliberadamente para defender un juicio"13. Salvo esta mención, Gibson considera que no hay mucho más que hacer con estos documentos, en vista de que la información que contienen es, en el mejor de los casos, errónea.

También James Lockhart -quien ha realizado una importante obra sobre los nahuas durante el período colonial y es uno de los impulsores de una visión más crítica y compleja de la realidad de estas sociedades- plantea, aunque de manera ambigua, la posibilidad de que los títulos hayan sido elaborados "bajo la presión de la situación y tal vez habiendo perdido el contacto con tradiciones locales relevantes, algunos pueblos recurrieron a la falsificación deliberada" ${ }^{\prime 4}$. Por otra parte, Serge Gruzinski, siguiendo las premisas de la historia de las mentalidades, afirma que la falsificación no solo es un hecho, sino que es exactamente lo que les da valor a estos textos. Desde su perspectiva, la falsedad de los títulos da testimonio de una visión menos aculturada (y, por lo tanto, más auténtica, en vista de su proximidad con las narraciones prehispánicas) de la manera de pensar de los indios del siglo XVII y XVIII ${ }^{15}$.

Stephanie Wood, alumna de Lockhart, es una de las investigadoras que más se ha adentrado en esta discusión sobre los títulos. Wood sugiere que pueden derivarse de una "memoria creativa y algunos pueden estar hábilmente falsificados" ${ }^{\text {". Sin }}$ embargo, dice esta historiadora, eso mismo sucede con algunas historias modernas, nacionales. La historiadora señala igualmente que las fechas que aparecen en los títulos, si bien no son comprobables, responden a la ingenuidad de los redactores, quienes creían que "los europeos que leyeran estos relatos muy probablemente los encontrarían creíbles si contenían abundancia de anclas temporales específicas"17. Finalmente, Wood sugiere que, además de los posibles préstamos e intercambios entre pueblos para su redacción, es probable que hubiera talleres dedicados a la

${ }^{13}$ Charles Gibson, "Prose Sources in the Native Historical Tradition", en Handbook of Middle American Indians, ed. H. E. Cline (Austin, Texas: University of Texas Press, 1975), vol. 15, parte 4: 321 .

${ }^{14}$ Lockhart, The Nahuas after, 414.

${ }^{15}$ Gruzinski, La colonización de lo imaginario, 105-106.

${ }^{16}$ Wood, "El problema de la historicidad", 181.

${ }^{17}$ Ibídem, 187. 
manufactura de dichos documentos, con el fin de cubrir el vacío dejado por la pérdida o ausencia completa de los mismos ${ }^{18}$.

Pero la tesis central que Wood quiere demostrar es que los títulos no son ni falsos ni tramposos y trata de demostrar su autenticidad de múltiples maneras. El núcleo de su argumentación se basa en sostener que "la corte no era el auditorio a quien se dirigían [los autores de los títulos] o, por lo menos, no el auditorio original"19. Para Wood, entonces, no hay falsificación posible en vista de que los títulos no debían ser expuestos a los españoles; su función era la de conservar y proteger la memoria del pueblo. La perspectiva de Wood sobre el origen y la función de estos documentos, así como su validez y autenticidad, pueden resumirse en este párrafo:

El hecho de vivir bajo la colonización estructuró la forma de la creación, marcó la evolución y determinó la versión final de muchos títulos, pero estos documentos, irónicamente, fueron hechos por y para los indígenas (...) Como fuentes históricas que ofrezcan información confiable y detallada de los linderos o de los actos oficiales de los líderes locales, los títulos exigen una precaución considerable en su manejo. Pero como fuentes de cándido folclore local, son verdaderos yacimientos en espera de prospectos ${ }^{20}$.

No obstante, nuestra perspectiva es otra. Para nosotros, considerar los contenidos de los títulos como "errores cándidos" de parte de los indígenas implica despojarlos de sus iniciativas y acciones políticas. Además, la lógica que subyace a estas afirmaciones sigue siendo la misma que la de aquellos autores que consideran el aspecto pragmático de estos textos como un defecto: Wood les devuelve la autenticidad quitándoles la intención política.

Finalmente, Margarita Menegus, historiadora mexicana especializada en la región de Toluca, trabajó con los Títulos Primordiales del pueblo de San Martín Ocoyoacac y concluyó, a contracorriente de sus colegas norteamericanos y francés, que los datos inexactos no son un engaño a los españoles ni un acto de ignorancia o de ingenuidad indígena, sino "un reclamo de los indios para que los reyes, aquellos que sucedieron a Carlos V, guardaran y respetaran los términos del pacto". Sin embargo, la autora anota que es "ocioso buscar en estos documentos la mentalidad indígena, puesto que no era una reelaboración de su historia, incitada esta por las consecuencias de la conquista, sino tan sólo una evocación del pacto original para

\footnotetext{
${ }^{18}$ Ibídem, 174-175. En el presente artículo nos concentraremos únicamente en dos de sus trabajos más recientes sobre los títulos: Wood, "El problema de la historicidad" y "The Social Against".

${ }^{19}$ Wood, "The Social against", 220.

${ }^{20}$ Ibídem, 221. Subrayado de autor.
} 
que fuera respetado" ${ }^{21}$. Así, Menegus lleva a cabo un procedimiento inverso al de Wood, pues insiste en el aspecto político y útil de los títulos, sin explorar la particularidad étnica o cultural de los textos en cuestión.

En resumen, los Títulos Primordiales han suscitado dudas en el ámbito académico y ello ha contribuido a una comprensión parcial de los mismos. Por un lado notamos cierta dificultad para explicar las transformaciones que se observan en estas versiones de la historia, muy poco afines a las más conocidas del siglo XVI. Por otro lado, pareciera que, puesto que estas narraciones fueron utilizadas en el campo jurídico o político, se puede poner en duda su autenticidad, y la única manera de devolvérsela es negando que tuvieran una utilidad concreta y práctica.

Nosotros, en cambio, no concebimos la utilización política como opuesta a la autenticidad cultural de los discursos. Para dar forma a nuestro argumento sobre los títulos haremos uso de la polémica mencionada al inicio de este trabajo sobre la autenticidad de las tradiciones inventadas en el Pacífico sur. Proponemos que las discusiones y críticas que surgieron del debate en Oceanía enriquecen la comprensión de las interpretaciones indígenas de la historia -como este corpus documental- y, al mismo tiempo, los procesos más generales de cambio cultural. Finalmente, veremos que es posible trasladar una problemática social contemporánea al análisis de un fenómeno histórico en localidades tan distintas como los archipiélagos de Oceanía y los valles centrales de la Nueva España.

\section{La controversia en el Pacífico sur}

Tras la descolonización de los países de Oceanía, diversos grupos sociales, muchas veces marcados por el factor étnico, emprendieron una labor de reconstrucción de la historia y las tradiciones locales. En todos los casos, esta tarea tuvo fines políticos. En Polinesia o Melanesia, por ejemplo, estas nuevas tradiciones buscaban constituir una historia y una identidad nacional en contextos de conformación de nuevos Estados-nación. En cuanto a Hawai o Nueva Zelanda, los grupos étnicos minoritarios buscaron un reconocimiento a su cultura y a su diferencia de parte del Estado previamente constituido. Veremos ahora cuáles fueron las interpretaciones que hicieron los especialistas sobre estas tradiciones.

A principios de los años 80, dos antropólogos que trabajaban de manera independiente -Roger Keesing y Alain Babadzan- se enfrentaron a fenómenos

\footnotetext{
${ }^{21}$ Margarita Menegus, "Los títulos primordiales de los pueblos de indios", en Dos décadas de investigación en historia económica comparada en América Latina. Homenaje a Carlos Sempat Assadourian, ed. M. Menegus (México: El Colegio de México, Centro de Investigación y Estudios en Antropología Social, Instituto Mora, Centro de Estudios sobre la Universidad, 1999), 154.
} 
sociales muy similares en localidades distintas: la kastom en Melanesia y Polinesia, respectivamente ${ }^{22}$. En sus análisis, estos dos antropólogos sostienen que la kastom es un instrumento ideológico de las élites políticas más occidentalizadas que se legitima con la idealización del pasado y de la cultura nativa. Esta ideología sería el resultado de la manipulación consciente de la cultura y de las tradiciones locales con el único fin de crear un discurso homogeneizador y simplificador que sirviera como herramienta de control político ${ }^{23}$.

Por su parte, Babadzan señala que esta ideología trata de resolver las contradicciones que existen entre la tradición y la modernidad del mundo industrial, pero que, en este intento, construye una imagen estereotipada de las tradiciones; la kastom, entonces, no solo se define a sí misma como la tradición auténtica, sino que, desde el punto de vista del antropólogo, margina toda posibilidad de revitalización cultural genuina ${ }^{24}$. Pero lo que resulta más paradójico para este antropólogo es que sus principales defensores son los sectores sociales más occidentalizados, aquellos que están más alejados de las "verdaderas" formas tradicionales de vida, aquellos cuyos valores están más implicados con la occidentalización: "Aquellos que acostumbraban burlarse del atraso de los 'salvajes' en nombre del Progreso y la Civilización son ahora (verbalmente) los más orgullosos defensores del mundo primitivo y los valores arcaicos" ${ }^{25}$.

Esta manipulación es perceptible, explican los autores, en vista de que los contenidos de la kastom difieren considerablemente de las realidades culturales locales que el especialista conoce, en lo referente tanto a la historia como a la cultura contemporánea. "Los modos de vida ancestrales que esta retórica evoca [la kastom] tienen muy poco en común con aquellos documentados históricamente, grabados por la etnografía o reconstruidos por la arqueología"26. Keesing concluye

\footnotetext{
${ }^{22}$ La kastom -de custom en inglés- significa "costumbre" en lengua criolla; este concepto se refiere al enorme conjunto de prácticas y creencias consideradas la "forma", la "particularidad" cultural de cada región, que se han convertido en la ideología nacionalista de varios países en Oceanía. Babadzan, "Kastom and Nation"; Eric Hobsbawm, The Invention of Tradition (Cambridge: Cambridge University Press [1983] 2000); Keesing, "Kastom in Melanesia"; "Creating the Past".

${ }^{23}$ El análisis, mucho más conocido, de fenómenos similares es el que elaboró Eric Hobsbawm sobre las tradiciones inventadas por los Estados-nación europeos al momento de su consolidación. Desde el punto de vista teórico, el trabajo de Hobsbawm es muy cercano al de Keesing y Babadzan, a pesar de que cada uno trabajó de manera independiente. Así, la mayoría de las premisas utilizadas por estos antropólogos también están presentes en la obra del historiador. Babadzan, "Kastom and Nation"; Hobsbawm, The Invention of Tradition; Keesing, "Kastom in Melanesia".

${ }_{25}^{24}$ Babadzan, "Kastom and Nation", 221.

${ }^{25}$ Ibídem, 186.

${ }^{26}$ Keesing, "Creating the Past", 19.
} 
que esta nueva tradición no toma en cuenta el pasado o la cultura verdaderos, puesto que fue elaborada en función de intereses y necesidades contemporáneas.

En síntesis, podemos decir que estos autores distinguen entre el pasado verdadero, objetivo y recuperable, y la "desviación" que representa la kastom. Así, esta tradición se percibe como una instrumentalización de la propia cultura, contradictoria con la vida "natural" de esas sociedades y con el pasado auténtico. Este pragmatismo es concebido como "un profundo abismo" entre la realidad y la construcción ideológica, entre la verdadera cultura y la tradición inventada ${ }^{27}$. Pero lo más importante es que estos especialistas consideran a la kastom como un cúmulo inconexo de elementos de la realidad -imprecisos y vacíos- sin ningún otro significado o lógica más que servir a intereses políticos ${ }^{28}$.

Frente a la caracterización de la kastom propuesta por Keesing y Babadzan, la reacción de otro grupo de especialistas de la región no se hizo esperar. En franco desacuerdo con el primero, Jocelyn Linnekin y Alan Hanson se acercaron a estas manifestaciones políticas y al problema de su autenticidad a partir de las propuestas teóricas de la antropología posmoderna. Para Jocelyn Linnekin, antropóloga de Hawai, especializada en cuestiones de etnicidad y de definición identitaria en esa isla, la distinción que Keesing y Babadzan hacen entre tradiciones inventadas y auténticas no es válida puesto que, para ella, todas las tradiciones $-\mathrm{y}$ culturas- son inventadas: "Construidas simbólicamente, las tradiciones no son, sin embargo, inauténticas; más bien, todas las tradiciones -occidentales e indígenasson inventadas en vista de que se construyen simbólicamente en el presente y reflejan preocupaciones y propósitos contemporáneos en vez de ser un legado pasivamente heredado" 29 .

Nos encontramos, entonces, frente a un análisis que no considera las tradiciones como estereotipos o invenciones, sino como interpretaciones del pasado. Para Linnekin, la tradición no es una manipulación de la "verdadera" cultura con fines exclusivamente políticos. Por ello, el objetivo de esta antropóloga no es, en principio, mostrar el grado de invención de estos discursos (con respecto del pasado verdadero); más bien, Linnekin busca hacer explícito que la tradición es algo flexible, maleable y que establece una estrecha relación con la etnicidad de un grupo al moldearla y ser moldeada por la propia etnicidad ${ }^{30}$.

\footnotetext{
${ }^{27}$ Ibídem, 35.

${ }^{28}$ Babadzan, "Kastom and Nation", 207; Keesing, "Kastom and Nation”,299.

${ }^{29}$ Linnekin, "Cultural Invention", 447.

${ }^{30}$ En este trabajo nos concentraremos en tres de sus artículos más representativos en cuanto a los problemas sobre la tradición y su autenticidad. Linnekin, "Defining Tradition"; "Cultural Invention"; "On the Theory and Politics".
} 
Sin embargo, en casi toda la obra de Linnekin, el dinamismo y la creatividad de las tradiciones que los hawaianos defienden se comparan con datos objetivos. Entonces, en su metodología, Linnekin termina por adoptar las oposiciones de los autores anteriores: al tratar de mostrar la maleabilidad de la tradición, la autora compara las divergencias que existen entre las representaciones del pasado que algunos grupos defienden con la "realidad" tanto histórica como contemporánea. Así, Linnekin afirma que "la tradición incluye elementos del pasado, pero este 'pasado' es erróneo. No corresponde a la experiencia de ninguna generación en particular" ${ }^{31}$. Hay que aclarar que, a diferencia de Keesing y Babadzan, ella considera esta característica de la tradición como una cualidad y no como un defecto: es la muestra de que la tradición es cambiante.

Así, aunque Linnekin busca trascender las propuestas de los autores precedentes, su análisis implica que existe un pasado objetivo desconocido (o ignorado) por los actores de los movimientos indígenas, los cuales actúan, nuevamente, en función de intereses políticos dictados en el presente.

El último antropólogo que revisaremos en este artículo, Allan Hanson, publicó un texto sobre los procesos de invención cultural de las tribus maoríes en Nueva Zelanda $^{32}$. Dicho texto llevó al extremo la línea constructivista ${ }^{33}$ de Linnekin y además desencadenó una gran polémica, incluso fuera del medio académico, en vista de que apareció en un momento de gran agitación política en Nueva Zelanda: la búsqueda de un Estado verdaderamente bicultural. Dentro de esta lucha, los intelectuales y políticos maoríes argumentaban que eran portadores de la verdadera tradición nativa y que querían continuar viviendo según esa tradición. Por eso, los antropólogos y el medio intelectual locales percibieron como un ataque a la validez de la cultura y de la lucha maorí la propuesta de Hanson de considerar todas las tradiciones como invenciones ${ }^{34}$.

Hanson está en contra de la idea de tradición entendida como un conjunto estable de realidades, transmitidas de generación en generación. Al igual que Linnekin,

\footnotetext{
${ }^{31}$ Linnekin, "Defining Tradition", 242.

${ }^{32}$ Hanson, "The Making of the Maori".

33 Llamamos constructivista a esta perspectiva porque considera que cualquier manifestación cultural está "construida" simbólicamente, en oposición a "heredada" o "transmitida".

${ }^{34}$ No es posible adentrarnos más en las múltiples críticas que recibió este artículo. Para ello existe un gran número de textos que lo hacen. Véanse Friedman, "Will the Real Hawaiian"; Turner, "Continuity and Constraint"; Webster, "Postmodernist Theory"; Hal B. Levine, "Comment on Hanson's 'The Making of the Maori"', American Anthropologist. (Washington D. C.), 93, num. 4 (1991): 444-446 y Robert Langdon, "Caucasian maoris: 16th Century Spaniards in New Zealand", American Anthropologist (Washington D. C.), 93, num. 4 (1991): 440-444, entre otros.
} 
este autor plantea que la cultura tradicional debe ser reconocida como una invención construida por los diversos grupos sociales en función del presente. A esta idea, ya sugerida por su colega, Hanson agrega que los antropólogos que han trabajado en la región a todo lo largo del siglo XX también han tenido injerencia dentro de estos procesos creativos de resignificación del pasado. En Nueva Zelanda, varios trabajos antropológicos tuvieron influencia en las construcciones culturales que los maoríes hicieron sobre sus tradiciones. Así, Hanson sugiere que los antropólogos también juegan un papel de "inventores" de la cultura. El autor reconoce dos momentos fundamentales de dichas invenciones:

La imagen de la cultura maorí que se desarrolló a principios del siglo XX se construyó principalmente gracias a algunos estudiosos predispuestos a analizar las instituciones locales en términos de migraciones de larga distancia, y que acariciaron el deseo político de asimilar a los maoríes a la cultura pakeha [grupos europeos colonizadores]. La imagen actual se ha inventado con el propósito de exaltar el poder de los maoríes en la sociedad de Nueva Zelanda, y se compone, principalmente, de aquellas cualidades maoríes que pueden contrastarse de manera positiva con los aspectos menos deseables de cultura pakeha ${ }^{35}$.

Para mostrar que las tradiciones tienen necesariamente un ingrediente ideológico, Hanson describe dos temas de la tradición maorí en donde detecta la huella dejada por los antropólogos y etnólogos de principios de siglo: la Gran Migración y el culto de Io ${ }^{36}$ Curiosamente, son dos elementos que presentan muchos puntos en común con ciertas tradiciones occidentales; en el caso de la migración, Hanson percibe rastros de las teorías difusionistas que permearon la antropología de principios de siglo; en el caso del culto de Io, la paternidad correspondería a la religión cristiana.

Pero lo que a juicio de este antropólogo resulta más paradójico es que, décadas después, los mismos maoríes -y los antropólogos que trabajan con ellos- se hayan apropiado de estas "invenciones" y hoy en día las consideren herencias tradicionales auténticas, es decir, precoloniales. Hanson explica que para los maoríes estos y otros temas refuerzan la particularidad étnica del grupo dentro del contexto político contemporáneo de lucha por el reconocimiento dentro del Estado neozelandés, lo cual explicaría su demanda: es el conflicto político lo que los mueve a reivindicar esas tradiciones. Vemos entonces cómo la perspectiva de este

\footnotetext{
${ }^{35}$ Hanson, "The Making of the Maori", 897.

${ }^{36}$ El primer tema que analiza Hanson es el mito de La Gran Migración, según el cual los maoríes habrían llegado a Nueva Zelanda provenientes de Tahití o de las Society Islands, organizados en distintas familias que dieron lugar a las tribus maoríes actuales. El otro tema es el culto de Io, definido como un culto "superior", puesto que es monoteísta, dedicado a una divinidad o "ser eterno, que se creó a sí mismo y es el creador de los otros dioses, el universo y todas las cosas". Ibídem, 891.
} 
antropólogo sigue muy de cerca la de su colega en Hawai: las tradiciones se construyen en el presente, en función de intereses políticos, pero ello, al menos en teoría, es visto como una cualidad ligada a la vitalidad y capacidad creativa de los grupos éticos en cuestión. En este sentido, las "distorsiones" que Hanson percibe en las nuevas tradiciones de los maoríes no son errores sino partes esenciales de toda tradición y de la cultura en general: "las invenciones son, precisamente, la materia de que la cultura está hecha" ${ }^{37}$.

Sin embargo, y a reserva de profundizar en este punto más adelante, queda claro que Hanson no logra explicar cuál es el proceso que lleva a los maoríes a aceptar esos discursos. A excepción del pragmatismo contemporáneo, pareciera que las elecciones de los maoríes no tienen ninguna otra lógica o por lo menos no de manera consciente. Dentro de su argumentación, el elemento determinante que da coherencia a la elección de los "objetos" que constituyen la nueva tradición parece ser el fin político, aun si ello no se percibe como un defecto de las tradiciones.

Con este autor se cierra la revisión de la polémica que tuvo lugar en la región de Oceanía a raíz de las nuevas tradiciones abanderadas por los grupos étnicos en contextos de lucha política por el reconocimiento o la participación de estos y los Estados poscoloniales. A continuación se presentará una síntesis de los problemas que se derivaron de esta discusión, con la ayuda de dos antropólogos más que criticaron, desde entonces, las posturas que se han descrito.

\section{Las políticas de la tradición}

Una de las primeras cuestiones que se detectan en esta discusión es que todos los autores confrontan las versiones del pasado defendidas por los grupos indígenas con aquellas que ellos conocen y que provienen de una investigación dentro del marco académico. De esta comparación resulta que la información de los nativos no coincide con la que los estudiosos conocen ya sea porque en el discurso indígena haya una amalgama proveniente del pasado precolonial y el pasado colonial; o bien porque aquello que se percibe como antiguo no es, en realidad, más que una práctica reciente. En este sentido, ambos grupos de autores distinguen entre la "verdadera" cultura o historia y las distorsiones o manipulaciones de los grupos contemporáneos: para Keesing y Babadzan, la kastom es un conjunto de prácticas y discursos elaborados de manera consciente con fines políticos que simplifican y estereotipan la cultura tradicional; para Hanson y Linnekin estas divergencias son la materia prima de la cultura. Es posible afirmar entonces que ambas posiciones conciben estas tradiciones como discontinuas con el verdadero pasado o la verdadera cultura, hay un desfase entre la "realidad" y la visión proyectada en estas tradiciones.

37 Ibídem, 898. 
Parecería entonces que una dicotomía atraviesa toda esta literatura: por un lado, las tradiciones genuinas asociadas a la cultura vivida "naturalmente" y a las tradiciones heredadas del pasado; por otro lado, las tradiciones inventadas, conscientemente construidas y con una retórica manipuladora. El problema de fondo es la asociación implícita entre inconciencia y autenticidad y, por lo tanto, de conciencia e inautenticidad ${ }^{38}$.

A este respecto, queda claro que en el acto mismo de distinguir entre historia e invención (aún si esta se percibe positivamente) dos problemas implícitos persisten: en primer lugar, la autoridad sobre la verdad es posesión del antropólogo -o del autor en general-, pues él es quien la define; en segundo lugar, la verdad que el autor define se opone, necesariamente, a modelos considerados populares o ideológicos que no gozan de veracidad ${ }^{39}$. El problema, entonces, es que los discursos, como la kastom, quedan reducidos a meras expresiones ideológicas, lo cual trae como consecuencia un análisis limitado de sus contenidos y de los motivos que llevaron a emitir y aceptar dichas tradiciones.

Si Keesing y Babadzan consideran el aspecto utilitario de las tradiciones como una instrumentalización externa y sin compromisos de parte de los actores, como una simple manipulación, Linnekin y Hanson se esfuerzan por tratar de trascender esta idea de cultura y señalan, enfáticamente, su dinamismo y su calidad interpretativa. Para ellos, la autenticidad de las tradiciones no se pone en duda por el hecho de ser utilizadas, sino que se considera una de sus características definitorias. El problema con sus análisis es que ninguno de los dos señala otra lógica que pudiera contribuir a la elaboración de estas tradiciones, determinadas exclusivamente por intereses contemporáneos. Una consecuencia de este razonamiento es que no se explica o no se profundiza en la información que contienen las tradiciones analizadas; como si el hecho de ser pragmáticas y responder a intereses del presente bastara para explicar porqué las tradiciones proyectan cierta información y no otra.

En el análisis que Hanson y Linnekin presentan no hay, entonces, continuidades o lógicas de otro tipo que condicionen la elaboración de estas "nuevas" tradiciones; pareciera que los elementos que las componen fueran elegidos entre cierto número de temas que se retoman en función de la utilidad que presentan para alcanzar los fines deseados. Sobre este particular, Jonathan Friedman sugiere que la idea de cultura que se halla detrás de este planteamiento se parecería a la de una aparador que contuviera accesorios independientes entre los cuales es posible escoger, según la ocasión y sin implicación alguna, aquellos que sirven mejor a los objetivos planteados, como si las diferentes culturas estuvieran constituidas de artefactos sin

${ }^{38}$ Jolly, "Specters of Inauthenticity", 49.

${ }^{39}$ Friedman, "The Past in the Future", 850. 
significado y sin ninguna articulación entre ellos. La continuidad o las especificidades culturales no intervienen en el proceso creativo de las tradiciones ${ }^{40}$.

Sin embargo, es evidente que estos discursos no surgen en un vacío; es necesario que una red social les dé un soporte; es esta red la que permite que la tradición reivindicada sea aceptada por la población; es decir, que si una tradición tiene significado no es únicamente debido a su funcionalidad. Existe, igualmente, un enorme conjunto de lógicas y prácticas culturales y sociales que operan al momento de la elección sin que ello entre en contradicción con el hecho de que la tradición tenga un aspecto pragmático. En este sentido, si un grupo social reacciona ante una circunstancia con el fin de proteger sus intereses, las motivaciones que lo llevarán a responder así como las estrategias que utilizará para cumplir su proyecto no pueden considerarse inventadas ${ }^{41}$.

Todas estas cuestiones pueden sintetizarse en el papel que cada uno de los autores asigna a los sujetos de estos procesos de definición identitaria. Keesing y Babadzan insisten en la incongruencia y manipulación de la kastom, lo cual les impide encontrarle sentido al ensamblaje de elementos de que se compone esta ideología. Tampoco ofrecen una explicación sobre la manera y razones por las cuales dicha ideología es aceptada y reproducida. En su análisis, dos grupos antagónicos participan de este discurso político, determinados por su posición en la estructura social y económica: el grupo hegemónico que manipula la cultura a su favor y la masa pasiva y oprimida que acepta las invenciones de la élite o que nada puede hacer frente a ellas sin profundizar en su capacidad de actuar o de participar: Así, al hablar de la folclorización reciente de Polinesia, Babdzan explica: "La población, que ha sido largamente cristianizada y que actualmente está ligada a la economía de mercado, es ahora inducida a adorar lo que antes se le obligaba a suprimir. Es presionada a regresar a sus tradiciones, a reintroducir el pasado, o algunos aspectos de ellos, en su vida diaria" ${ }^{42}$.

En cuanto a los trabajos de Linnekin y Hanson, su reacción es, justamente, la de ocupar el extremo opuesto. En sus análisis se reconoce la participación activa de los actores sociales en la configuración de su cultura. Estos contribuyen enérgicamente en el proceso de construcción de las tradiciones, salvo que todo el

\footnotetext{
${ }^{40}$ Friedman, "Will the Real Hawaiian", 759, 670.

${ }^{41}$ "Si la cultura solo se concibe como un conjunto de artefactos, la cuestión de la continuidad no puede, ni siquiera, ser planteada propiamente como un fenómeno social. Ello se debe a que las continuidades, más allá de los cambios en las formas culturales, no son comprensibles en las formas mismas sino que deben descubrirse en las motivaciones y estrategias, las intencionalidades de los sujetos sociales en el tiempo y el espacio". Ibídem, 760.

${ }^{42}$ Babadzan, "Kastom and Nation", 220.
} 
énfasis está puesto en este aspecto: el trabajo creativo implementado por los individuos, pero sin vínculos sociales o históricos.

Desde nuestra perspectiva, sin embargo, ambas características -el nivel estructural y la agencia de los individuos-intervienen en el proceso de recrear las tradiciones; en otras palabras, las tradiciones son universos significantes para los individuos y las colectividades, motivadas por los sujetos que viven en un mundo social específico. Así como no es posible negar el aspecto pragmático y utilitario de la cultura, tampoco es sostenible la idea de que estas tradiciones carecen de una dimensión histórica o temporal que pueda establecer continuidades con situaciones previas.

Las reflexiones que hemos desarrollado en esta sección tienen como fin proponer una noción de cultura $-\mathrm{y}$ de tradición, particularmente- que tome en cuenta las críticas que hemos presentado. En consecuencia, consideraremos las tradiciones como modelos del pasado determinados tanto por las necesidades contemporáneas de autodefinición (por lo cual no es gratuito que muchos de estos discursos salgan a la luz en contextos de lucha política) como por las lógicas culturales que contribuyen a determinar la elección de los elementos que constituirán dicha tradición. A ello hay que agregar un último aspecto de vital importancia: la tradición es también un proyecto de futuro, del futuro que el grupo en cuestión persigue y quiere definir, según sus propios criterios, acomodos y valores para guiar su desarrollo y su posibilidad de reproducción social.

\section{Conclusión: los títulos, políticos y auténticos}

Tras haber abordado las discusiones que los académicos plantearon al acercarse a fenómenos sociales como la kastom, regresaremos, a modo de conclusión, a los Títulos Primordiales con el fin de ofrecer una interpretación de los mismos que logre explicar la complejidad y la heterodoxia de la información que contienen. Para ello es necesario retomar la discusión sobre la originalidad de los títulos en donde la dejamos. Se recordará que en los análisis expuestos por los historiadores que han trabajado con los títulos se percibe un conflicto entre las funciones que estos documentos cumplen y la intención de sus autores, vinculado -entre otras cosas- al hecho de que los títulos contienen difieren de las más conocidas por los especialistas. Frente a estos textos, los historiadores se han preguntado: ¿fueron falsificaciones para engañar a los españoles?, ¿son genuinos porque no estaban dirigidos a las cortes $\mathrm{y}$, por lo tanto, no trataban de engañar a nadie?

Desde nuestra perspectiva, los Títulos Primordiales tuvieron, sin duda, una función política y legal: proteger la propiedad territorial de cada pueblo. Como mencionábamos más arriba, la huella de oralidad que se percibe en estos documentos sirve de pauta para mostrar que si las narraciones contenidas en los 
títulos eran un producto interno de cada pueblo, el hecho de ponerlas por escrito tuvo, necesariamente, la finalidad legal de tener documentos que presentar ante la corte.

Es por ello que esta utilización no implica que estos documentos fueran falsificaciones premeditadas; tampoco podemos hablar de manipulación en vista de que ello supone que existe una versión "verdadera", "real", lo cual no podemos probar. A continuación trataremos de mostrar que si bien tuvieron una función práctica, los títulos están compuestos por elementos significativos de la propia historia de cada pueblo; que las narraciones de los títulos dejan ver su propia versión de la historia local.

La primera entrada para resolver estas cuestiones será mostrar quiénes son las voces que se descubren en estas narraciones, en vista de que no hay información documental sobre los autores concretos de estos documentos. Así, nos preguntaremos acerca de cuál era la situación social y política de los pueblos que presentaron títulos entre mediados del siglo XVII y finales de siglo XVIII. A diferencia de la situación de los pueblos en el siglo XVI, varios autores proponen que para la época que nos interesa los pueblos eran cada vez más independientes de las grandes instituciones - tanto coloniales como prehispánicas- tales como la encomienda, las órdenes religiosas e incluso los grandes altépetl. En este sentido, la tendencia en los valles centrales de la Nueva España fue hacia la fragmentación del paisaje en múltiples pueblos que rompieron incluso con las categorías de cabecera y sujeto. A ello hay que agregar un despunte demográfico tras la brutal caída poblacional, una de las más importantes, acaecida hacia 1580, así como la tensión reinante alrededor de la posesión de la tierra entre pueblos y con las haciendas. Por otra parte, el cambio administrativo que trajo consigo el reinado de la casa borbónica en España a partir del siglo XVIII, así como las políticas que dicha administración puso en marcha para tratar de regular la posesión de la tierra, fomentaron la exhibición de documentos relativos a la posesión de las tierras comunales de cada pueblo ${ }^{43}$.

\footnotetext{
${ }^{43}$ Este esbozo de la situación colonial de finales del siglo XVII y XVIII se basa en la tesis de Lockhart de las tres etapas del período colonial. Para mayor información a este respecto, véase Georges A. Collier, Renato I. Rosaldo y John D. Wirth, eds., The Inca and Aztec States 1400-1800. Anthropology and History (Los Angeles, Nueva York: Academic Press, 1982); Tom Cummins y Elizabeth Hill Boone, eds., Native Traditions in the Postconquest World (Washington D. C.: Dumbarton Oaks, 1998); Herbert Harvey, ed., Explorations in Ethnohistory: Indians of Central Mexico in the 16th Century (Albuquerque: University of New Mexico Press, 1984); James Lockhart, "Views of Corporate Self and History in Some Valley of Mexico Towns in Late Seventeenth and Eighteenth Centuries", en The Inca and Aztec States 1400-1800. Anthropology and History, eds. G. A. Collier, R. I. Rosaldo y J. Wirth, (New York, London, París: Academic Press, 1982), 367-393; "Postconquest Nahua Society and Concepts Viewed through Nahuatl Writings", Estudios de Cultura Náhuatl
} 
Dentro de este contexto, los contenidos de los títulos resultan mucho más comprensibles, pues las transformaciones en el contenido de las tradiciones históricas plasmadas en ellos no responden, desde nuestro punto de vista, a un intento por engañar a los españoles ni a una ingenuidad o ignorancia en el conocimiento de la historia local. Tienen que ver, más bien, con cambios concretos en la propia sociedad indígena; después de por lo menos un siglo y medio de intercambios y contactos directos con los europeos, la vida social y cultural de dichas sociedades es, necesariamente, una síntesis de ambas vetas: la náhuatl y la española. Los actores que se descubren en las narraciones de los títulos apelan, al mismo tiempo, a su vertiente indígena y a la colonial.

Es cierto también que la situación de los indios que redactaron los Títulos Primordiales difiere notablemente del contexto en que se redactaron las crónicas indígenas del siglo XVI y que, en los análisis que se han hecho de estos documentos, sirven como contrapunto. Los autores del siglo XVI pertenecieron, en su mayoría, a los grupos nobles indígenas, en franca crisis, que se hallaban aún bajo el impacto de la guerra de conquista y buscaban conservar y transmitir la historia de sus linajes en vías de desaparición. En cambio, los pueblos que presentan los títulos ya no tenían vínculos estrechos con los grandes linajes prehispánicos; la información que se refleja en estos documentos era la historia local, en posesión de los notables del pueblo. En cuanto a los objetivos de estos autores, también difieren de los del siglo XVI. En el caso de los títulos el fin que se perseguía era encontrar un procedimiento jurídico que les permitiera proteger sus tierras.

Desde esta perspectiva, podemos afirmar que la información que dichos documentos contienen no es ni errónea ni accesoria, sino más bien congruente con la realidad social de sus autores. Además, los criterios que guiaron la elección de los temas en los títulos no pueden comprenderse como un simple pragmatismo orientado a convencer o complacer a los juzgados españoles. Ello implicaría, como con la kastom, que cada cultura está compuesta de accesorios que se utilizan o se desechan según la ocasión, sin compromiso alguno de parte de quienes redactaron estos textos.

Creemos, en cambio, que los aspectos "heterodoxos" que encontramos en los títulos (la exaltación a Cortés, la plena conversión religiosa, etc.) eran, en realidad, interpretaciones significativas para los propios autores; era su propia versión de la historia. Así, las fechas y nombres que aparecen en los títulos pueden entenderse

(México), 20 (1990): 3 -13; The Nahuas after; y James Lockhart e Ida Altman, eds., Provinces of Early Mexico: Variants of Spanish American Regional Evolution (Los Angeles: UCLA Latin American Center, 1976). 
como huellas importantes que permanecieron, justamente por su utilidad, dentro de las tradiciones históricas de estos pueblos y no como elementos sin significado para los autores ${ }^{44}$.

En esta línea de pensamiento, la idea de un préstamo de símbolos culturales -con el fin de convencer o engañar a las cortes españolas-, sin coherencia para el grupo que las elabora, supone una relativización indispensable de la propia cultura; implica también una manipulación de las tradiciones con fines pragmáticos, totalmente desvinculada de cualquier lógica cultural propia. Cabe señalar, entonces, que en los títulos no hay indicios que permitan suponer que la verdad que los redactores conocían y aceptaban fuera otra distinta de la que transmiten en estas narraciones. Resulta más lógico encontrar elementos para afirmar que las tradiciones históricas que se compilaron en estos documentos responden a un conjunto de realidades culturales propias ${ }^{45}$.

De nuevo, el ejemplo del santo resulta muy ilustrador, pues, a pesar de su origen español, en los títulos aparece como el padre fundador del pueblo, asociado, en muchas ocasiones, a un mito de fundación con raíces prehispánicas; es también el representante y el guardián de sus tierras, en continuo diálogo con sus fieles. Pero su importancia no es ni el síntoma de una aculturación completa y destructora de la cultura náhuatl ni el préstamo calculado para complacer a los españoles, a costa de las creencias propias de estos grupos indígenas. Se trata más bien de una identificación con este símbolo, puesto que permite reflejar, al mismo tiempo, las necesidades contemporáneas del grupo -como la autonomía interna, la independencia del pueblo, la protección de las tierras-y las lógicas culturales que guían estas transformaciones, tendiendo siempre hacia una continuidad con prácticas precedentes.

Resulta, entonces, que para los redactores, e incluso para los receptores de los títulos, no parece haber ninguna contradicción entre los elementos españoles incorporados a la tradición histórica de los pueblos y las prácticas indígenas que los

\footnotetext{
${ }^{44}$ Un ejemplo de que esta apropiación no es fortuita ni azarosa es que, si bien hay muchas confusiones entre los nombres de los personajes españoles y sus títulos, la distinción entre personajes "civiles" y personajes "religiosos" se mantiene invariablemente. Véase, por ejemplo, el Título Primordial de Los Reyes en López, Los Títulos Primordiales, 309-320.

${ }^{45}$ A este respecto, resulta pertinente la noción creada por Lockhart, The Nahuas after, 445446, de double mistaken identity: en los vínculos que establecen nahuas y españoles, cada parte considera que la otra conoce las mismas formas, instituciones o conceptos que ella, y además asume que el significado de ese concepto es igual para el otro grupo y que, por lo tanto, funciona de modo semejante a su propio universo cultural. Ello hace prácticamente imposible que cada parte se entere de la interpretación que el otro grupo elabora. En pocas palabras, la relativización de la propia cultura para satisfacer a la otra resulta muy difícil de probar.
} 
rodean; esto es un criterio establecido desde el presente, en gran parte por los académicos $^{46}$. La sociedad que se percibe en estos documentos parece concebirse como el resultado de estas dos ramas culturales, una sociedad que constituye su legitimidad integrando elementos previos y posteriores al contacto ${ }^{47}$.

Para terminar, más allá del origen puntual de cada elemento que constituye el discurso de los títulos, consideramos que otro nivel de análisis permite también señalar la legitimidad de estos textos. Las motivaciones que llevan a los pueblos a presentar los títulos en las cortes judiciales así como el recurso de apelar a su cultura o su tradición para lograrlo no pueden, desde nuestra perspectiva, considerarse inventados o manipulados. Estos textos responden a necesidades completamente legítimas y concretas: la posibilidad de reproducción social y cultural del grupo. Que dicho grupo utilice conscientemente su pasado, su cultura o su tradición para alcanzar sus metas es simplemente un reflejo más de su vitalidad; en este sentido, una tradición viva no es un fin en sí mismo conservado y protegido de los vientos de la interacción y el intercambio, sino un proyecto, resultado de la sociedad que lo produce $\mathrm{y}$, por lo tanto, susceptible al cambio.

Esta reflexión nos lleva a concluir con una definición más elaborada de qué es la tradición. Con base en los títulos y en la polémica sobre la autenticidad de las tradiciones en el Pacífico sur, parece más pertinente comprender la tradición como revisiones del pasado estructuradas con base en un equilibrio entre los contextos sociales y políticos que la desatan y las lógicas culturales o continuidades del grupo que le dan peso y significado; estas revisiones contribuyen a elaborar o difundir una identidad común y al mismo tiempo convocan en torno al proyecto social, al futuro que necesariamente proponen. Esta es la razón de que los títulos puedan ser políticos, útiles y, al mismo tiempo, genuinos: son coherentes con el grupo que los reivindica, pues son acordes con las apuestas identitarias o proyectos sociales del mismo.

\footnotetext{
${ }^{46}$ Llama la atención que, de los 19 documentos que encontramos en el AGN, 12 fueron reconocidos por los juzgados como válidos. En ese sentido, podemos señalar que la idea de falsedad basada en la inexactitud de la información implica una concepción particular de verdad que pertenece al paradigma contemporáneo, razón por la cual los académicos han sospechado de la autenticidad de documentos que ni las comunidades ni, en muchos casos, los jueces consideraron dudosos. Véase López, Los Títulos Primordiales, 350.

47 En este sentido, habría que preguntarse hasta qué punto, en la literatura histórica y antropológica contemporánea, lo indígena sigue concibiéndose como prehispánico. En el caso de los títulos, los elementos indígenas de la tradición ya van de la mano con aquellos que llegaron con la conquista, sin que ello represente una pérdida o un empobrecimiento de la cultura de estos grupos.
} 


\section{Bibliografía}

Babadzan, Alain. "Kastom and Nation Building in the South Pacific". En Processes of Interthnic Relations in Latin America, Southeast Asia and the Pacific, ed. Remo Guidieri, 199-228. Huston: Rothko Chapel and University of Texas Press, 1988.

Collier, Georges A., Renato I. Rosaldo y John D. Wirth, eds. The Inca and Aztec States 1400-1800. Anthropology and History. Los Angeles, Nueva York: Academic Presspp, 1982.

Cummins, Tom y Elizabeth Hill Boone, eds. Native Traditions in the Postconquest World. Washington D.C.: Dumbarton Oaks, 1998.

Fischer, Edward F. y R. Mckeena Brown, eds. Mayan Cultural Activism in Guatemala. Austin, Texas: Austin University Presspp, 1996.

Florescano, Enrique. "El canon memorioso forjado por los Títulos Primordiales". Colonial Latin American Historical Review (Hamilton, Estados Unidos), 11, núm. 2 (2002): 183-230.

Foweraker, Joe y Ann Craig, eds. Popular Movements and Political Change in Mexico. Boulder: Rienner, 1990.

Fox, Jonathan, ed. The Challenge of Rural Democratisation: Perspectives from Latin America and the Philippines. Londres: Cass, 1990.

Friedman, Jonathan. "The Past in the Future: History and Politics of Identity". American Anthropologist (Catalunya), 94, núm. 4 (1992): 837-859.

. "Will the Real Hawaiian Please Stand: Anthropologists and Natives in the Global Struggle for Identity". Bijdragen Tot de Taal-Land- en Volkenkunde. Número especial: Politics, Traditions and Change in the Pacific (Leiden), 149 (1993): 737-767.

. Cultural Identity and Global Processes. Londres: Sage Publications, 1994.

. "From roots to routes. Tropes for trippers". Anthropological Theory (Londres), 2, núm. 1 (2002): 21-36. 
. "Modernity and Other Traditions". En Critically Modern. Alternatives, Alterities, Anthropologies. ed. B. M. Knauft. Bloomington, Indianapolis: Indiana University Press, 2002.

- "The dialectic of cosmopolitanization and indigenization in the contemporary world system: Contradictory configurations of class and culture". En The Blackwells Companion to the Anthropology of Politics, eds. D. Nugent y J. Vincent, 1-20. Oxford: Blackwell, 2004.

Gibson, Charles. "Prose Sources in the Native Historical Tradition". En Handbook of Middle American Indians, ed. H. E. Cline. Vol. 15, parte 4, 311-321. Austin, Texas: University of Texas Press, 1975.

Gruzinski, Serge. La colonización de lo imaginario. Sociedades indígenas y occidentalización en el México español. Siglos XVI, XVIII. México: Fondo de Cultura Económica, 1993.

Hanson, Alan. "The Making of the Maori: Cultural Invention and its Logic". American Anthropologist (Washington D. C.), 91, núm. 4 (1989): 890-902.

Harvey, Herbert, ed. Explorations in Ethnohistory: Indians of Central Mexico in the 16th Century. Albuquerque: University of New Mexico Press, 1984.

Haskett, Robert. "Indian Town Government in Colonial Cuernavaca". Hispanic American Historical Review (Durham, Estados Unidos), 67 (1987): 203231.

. "Visions of Municipal Glory Undimmed: The Nahuatl Town Histories of Colonial Cuernavaca". Colonial Latin American Historical Review (Albuquerque, Estados Unidos), 1, núm. 1 (1992): 1-35.

Hobsbawm, Eric. The Invention of Tradition. Cambridge: Cambridge University Press [1983] 2000.

Jolly, Margaret. "Specters of Inauthenticity". The Contemporary Pacific (Honolulu), 4, núm. 1 (1992): 42-72.

Kamakawiwo'ole Osorio, Jonathan. ""What Kine Hawaiian Are You?" A Mo'oleo about Nationhood, Race, History, and the Contemporary Sovereignty Movement in Hawai'i". The Contemporary Pacific (Honolulu), 13, núm. 2 (2001): 359-379. 
Keesing, Roger. "Kastom in Melanesia: An Overview". Mankind. Número especial. Reinventing Traditional Culture: The Politics of Kastom in Island Melanesia, eds. Roger Keesing y Robert Tonkinson, 13 (1982): 1-5.

"Creating the Past: Custom and Identity in the Contemporary Pacific". The Contemporary Pacific (Honolulu), 1 (1989): 19-42.

Langdon, Robert. "Caucasian maoris: 16th Century Spaniards in New Zealand". American Anthropologist (Washington D. C.), 93, num. 4 (1991): 440-444.

Lawson, Stephanie. "The Tyranny of Tradition: Critical Reflections on Nationalist Narratives in the South Pacific". En Narratives of Nation in the South Pacific, eds. T. Otto y N. Thomas. Vol. 19: 15-31. Amsterdam: Harwood Academic Publishers, 1997.

Levine, Daniel, ed. Constructing culture and Power in Latin America. Michigan: Michigan University Press, 1993.

Levine, Hal B., "Comment on Hanson's 'The Making of the Maori"'. American Anthropologist (Washington D. C.), 93, num. 4 (1991): 444-446.

Linnekin, Jocelyn. "Defining Tradition: Variations on the Hawaiian Identity". American Ethnologist (Arlington, Estados Unidos), 10 (1983): 241-252.

"Cultural Invention and the Dilemma of Authenticity". American Anthropologist (Washington D. C.), 93 (1991): 446-448.

. "On the Theory and Politics of Cultural construction in the Pacific". Oceania. Número especial, The Politics of Tradition in the Pacific (Sidney, Australia), 62, núm.4 (1992): 249-263.

Linnekin, Jocelyn y Lin Poyer, eds. Cultural Identity and Ehtnicity in the Pacific. Honolulu: University of Hawai'i Press, 1990.

Lockhart, James. "Views of Corporate Self and History in Some Valley of Mexico Towns in Late Seventeenth and Eighteenth Centuries". En The Inca and Aztec States 1400-1800. Anthropology and History, eds. Collier, G. A., R. I. Rosaldo y J. Wirth, 367-393. Nueva York, Londres, París: Academic Press, 1982.

"Postconquest Nahua Society and Concepts Viewed through Nahuatl Writings". Estudios de Cultura Náhuatl (México), 20 (1990): 3 -13. 
. The Nahuas after the Conquest. A Social and Cultural History of Indians of Central Mexico 16th through 18th Centuries. Standford, California: Standford University Press, 1992.

Lockhart, James e Ida Altman, eds. Provinces of Early Mexico: Variants of Spanish American Regional Evolution. Los Angeles: UCLA Latin American Center, 1976.

López, Paula. Los Títulos Primordiales del centro de México. Introducción y catálogo. México: Dirección General de Publicaciones; Conaculta, 2003.

Maybury-Lewis, David. Indigenous Peoples, Ethnic Groupes and the State. Boston: Allyn and Bacon, 1997.

Menegus, Margarita. "Los Títulos Primordiales de los pueblos de indios". En Dos décadas de investigación en historia económica comparada en América Latina. Homenaje a Carlos Sempat Assadourian, ed. M. Menegus, 137161. México: El Colegio de México, Centro de Investigación y Estudios en Antropología Social, Instituto Mora, Centro de Estudios sobre la Universidad, 1999.

Navarrete, Federico. "Mito, historia y legitimidad política: las migraciones de los pueblos del valle de México". Tesis doctoral, UNAM, México, 2001.

Oudijk, Michel R. y M. Romero Frizzi. "Los Títulos Primordiales: un género de tradición mesoamericana". Relaciones (Zamora, México), 24, núm. 95 (2003): 17-43.

Roskamp. "Los 'Títulos Primordiales' y la fundación prehispánica de los pueblos michoacanos: algunas reflexiones". Boletín del Archivo General Agrario (México), 15 (2001): 5-21.

Thomas, Nicholas. "The inversion of tradition". American Ethnologist (Arlington, Estados Unidos), 19, núm. 2 (1992): 213-232.

Turner, James West. "Continuity and Constraint: Reconstructing the Concept of Tradition from a Pacific Perspective". The Contemporary Pacific (Honolulu), 9, núm. 2 (1997): 345-381.

Urban, Greg y Joel Sherzer, eds. Nation States and Indians in Latin America. Austin, Texas: Austin University Press, 1991. 
Van Cott, Donna Lee, ed. Indigenous Peoples and Democracy in Latin America. Nueva York: St. Martin's Press, Inter-American Dialogue, 1994.

Warren, Kay. The Simbolism of Subordination: Indian Identity in a Guatemala Town. Austin, Texas: University of Texas Press, 1989.

. Indigenous Movements and their Critics: Pan-Mayan activism in Guatemala. Princeton, NJ: Princeton University Press, 1998.

Webster, S. "Postmodernist Theory and the Sublimation of Maori Culture". Oceania (Sidney, Australia), 63 (1993): 222-239.

Welchman Gegeo, David. "Cultural Rupture and Indigeneity: The Challenge of (Re)visioning 'Place' in the Pacific". The Contemporary Pacific (Honolulu), 13, núm. 2 (2001): 491-507.

WIttersheim, Éric. "Les chemins de l'authenticité. Les anthropologues et la Renaissance mélanésienne". L'Homme (París), 151 (1999): 181-206.

Wood, Stephanie. "Don Diego García Mendoza: A Techialoyan Mastermind?". Estudios de Cultura Náhuatl (México), 19 (1989): 245-268.

. "El problema de la historicidad de los títulos y los códices Techialoyan." En De Tlacuilos y escribanos. Estudios sobre documentos indígenas coloniales del centro de México, Colección Memorias. Zamora, eds. X. Noguez y S. Wood, 1-221. Michoacán Zinacantepec, Estado de México: El Colegio de Michoacán, El Colegio Mexiquense, 1998.

. "The Social against the Legal Context of Nahuatl títulos". En Native Traditions in the Postconquest World, ed. Elizabeth Hill Boone, 201-231. Washington D. C.: Dumbarton Oaks, 1998.

Fecha de recepción: 29 de abril de 2005.

Fecha de aceptación: 23 de agosto de 2005. 